\title{
Síndrome antifosfolipídico en pediatría: a propósito de un caso
} The antiphospholipid antibody syndrome in pediatrics: a case report

\author{
Dra. Miranda Fernándeza , Dra. Paula Tasso ${ }^{a}$, Dr. Ignacio Tedeschini ${ }^{a}$ Dra. Julia Lómez ${ }^{a}$, Dra. María V. Lópeza \\ y Dr. Ariel Cheistwer ${ }^{a}$
}

\section{RESUMEN}

El síndrome antifosfolipídico (SAF) es infrecuente en la edad pediátrica $(3 \%)$ y se presenta como eventos trombóticos de lechos vasculares y/o abortos espontáneos, asociado a la presencia de anticuerpos antifosfolipídicos (aFL). Este síndrome puede ser primario o asociado a alguna enfermedad sistémica subyacente.

Se presenta el caso de una niña de 12 años con hemiparesia faciobraquiocrural derecha y alteración en la marcha de aparición aguda, en la cual se confirma un accidente cerebrovascular (ACV) isquémico por trombosis de la arteria cerebral media asociado a aFL positivos (anticuerpo anticardiolipina, anticoagulante lúpico y anticuerpo anti- $\beta 2$ glicoproteína). Cumple con los criterios para realizar diagnóstico de síndrome antifosfolipídico. Luego de iniciar el tratamiento, la paciente evoluciona de manera favorable.

Se trata de una patología infrecuente y de presentación variable, por lo que requiere un alto sentido de alerta por parte del equipo de salud para evitar retrasos en el diagnóstico y el tratamiento, y disminuir su morbimortalidad.

Palabras clave: sindrome antifosfolipídico, inhibidor de coagulación del lupus, trombosis, accidente cerebrovascular, pediatría.

\begin{abstract}
Antiphospholipid syndrome (APS) is infrequent at pediatric age $(3 \%)$ and is characterized by venous or arterial thrombosis and / or spontaneous abortions. APS occurs either as a primary condition or in the setting of an underlying disease.

This is a case of a 12-year-old girl with a right hemiparesis and acute disturbance in gait, in which an ischemic cerebrovascular accident (CVA) due to middle cerebral artery thrombosis associated with positive antiphospholipid antibodies is confirmed (anticardiolipin antibody, lupus anticoagulant and anti- $\beta 2$-glycoprotein antibody), fulfilling the criteria for the diagnosis of antiphospholipid syndrome. After starting treatment accordingly, the patient evolves favorably.

As this pathology is infrequent and of variable presentation, it requires a high sense of alert from the health team to avoid delays in diagnosis and treatment.

Key words: Antiphospholipid syndrome, lupus coagulation inhibitor, thrombosis, stroke, pediatrics.
\end{abstract}

a. Unidad 6, Clínica Pediátrica, Hospital de Niños Ricardo Gutiérrez, Ciudad Autónoma de Buenos Aires, Argentina.

Correspondencia:

Dra. Miranda Fernández: mirulfernandez@gmail.com

Financiamiento: Ninguno.

Conflicto de intereses: Ninguno que declarar.

Recibido: 12-1-2021

Aceptado: 8-6-2021 http: / / dx.doi.org/10.5546/ aap.2021.e631

Cómo citar: Fernández M, Tasso P, Tedeschini I, Lómez J, et al. Síndrome antifosfolipídico en pediatría: a propósito de un caso. Arch Argent Pediatr 2021;119(6):e631-e635.

\section{INTRODUCCIÓN}

El síndrome antifosfolipídico (SAF) es una enfermedad autoinmune sistémica de etiología desconocida, caracterizada por la aparición de eventos tromboembólicos y/o abortos espontáneos, asociada a la presencia de anticuerpos antifosfolipídicos (aFL) (anticardiolipina, anticoagulante lúpico y anti- $\beta 2$ glicoproteína). Es una patología que se presenta característicamente en la edad adulta, pero su incidencia en pediatría está en aumento. ${ }^{1}$

El espectro es muy variable e incluye desde pacientes oligosintomáticos hasta una enfermedad amenazadora para la vida, como es el SAF catastrófico. Cualquier órgano puede verse afectado como consecuencia de la trombosis de vasos grandes o pequeños. ${ }^{1,2}$

Este síndrome puede presentarse de manera aislada (primario o idiopático) o asociado a otra enfermedad, de las cuales la más frecuente es el lupus eritematoso sistémico. ${ }^{2}$

Se presenta el caso de una niña de 12 años con accidente cerebrovascular (ACV) isquémico por trombosis de la arteria cerebral media en la que se llega al diagnóstico de síndrome antifosfolipídico.

\section{CASO CLÍNICO}

Paciente de sexo femenino, de 12 años, con antecedente de hipoacusia bilateral desde el nacimiento, que consultó en el servicio de urgencias del hospital por cefalea y mareos de un mes de evolución; en las últimas 48 horas se agrega desviación de la comisura labial hacia la derecha y alteración en la marcha. En el examen físico, se la valoró en buen estado general, afebril y hemodinámicamente compensada; vigil, reactiva y conectada. Se constató hemiparesia faciobraquiocrural derecha, sin signos de hipertensión endocraneana. Se realizó tomografía 
computada (TC) de cerebro, donde se observaron lesiones hipodensas periventriculares asumidas como áreas de isquemia. Por sospecha de ACV isquémico, se decidió su internación. Se realizó laboratorio completo, que informó plaquetopenia (plaquetas $\left.66000 / \mathrm{mm}^{3}\right)$, anemia $(\mathrm{Hb} \mathrm{10,3} \mathrm{g} / \mathrm{dL}$ ), tiempo de Quick $88 \%$ y KPTT prolongado de 115 segundos (no corregía con el agregado de plasma, lo que denotaba la presencia de inhibidores de la coagulación). Además, se solicitaron: angiorresonancia magnética, que evidenció obstrucción del flujo a nivel de la arteria cerebral media (Figura 1); resonancia magnética (RMN) de cerebro, donde se observó infarto subagudo en el territorio perforante de la arteria cerebral media izquierda e infarto de evolución aguda cortical parietal izquierdo (Figura 2); ecocardiograma, normal, y ecografía Doppler de vasos del cuello con flujo conservado.

Dada la presencia de ACV isquémico asociado a manifestaciones hematológicas, se sospechó SAF y se pidieron los siguientes estudios complementarios: aFL con técnica ELISA (anticuerpo anticardiolipina IgM e IgG con títulos de $31 \mathrm{U} / \mathrm{mL}$ y $58 \mathrm{U} / \mathrm{mL}$, respectivamente; anticuerpo anti- $\beta 2$-glicoproteína IgM e IgG con títulos de $37 \mathrm{U} / \mathrm{mL}$ y $48 \mathrm{U} / \mathrm{mL}$ respectivamente, y anticoagulante lúpico) cuyos valores de corte son títulos mayores a $40 \mathrm{U} / \mathrm{mL}$ positivo, entre 20 y $40 \mathrm{U} / \mathrm{mL}$ positivo débil y menor a $20 \mathrm{U} / \mathrm{mL}$ negativo; perfil inmunológico completo (C3 bajo, anticuerpos antinucleares (ANA) positivos [1:320, patrón moteado], inmunoglobulinas $\mathrm{G}$ aumentadas). Con dichos resultados, se confirmó el diagnóstico de $\mathrm{ACV}$ isquémico por SAF primario asociado a manifestaciones de un cuadro lupoide: plaquetopenia, C3 bajo y ANA positivo (ver criterios diagnósticos de SAF en la Tabla 1). Los resultados de los anticuerpos antifosfolipídicos fueron revalidados a las 12 semanas: anti- $\beta 2$-glicoproteína $\operatorname{IgM}$ e IgG de $21 \mathrm{U} / \mathrm{mL}$ y $28 \mathrm{U} / \mathrm{mL}$, respectivamente; y anticardiolipina IgM e IgG de $22 \mathrm{U} / \mathrm{mL}$ y $30 \mathrm{U} /$ $\mathrm{mL}$, respectivamente.

Es importante aclarar que, entre los estudios iniciales, se realizó la prueba de Coombs, que resultó negativa, y otros estudios para descartar etiología infecciosa: IgG e IgM para virus de

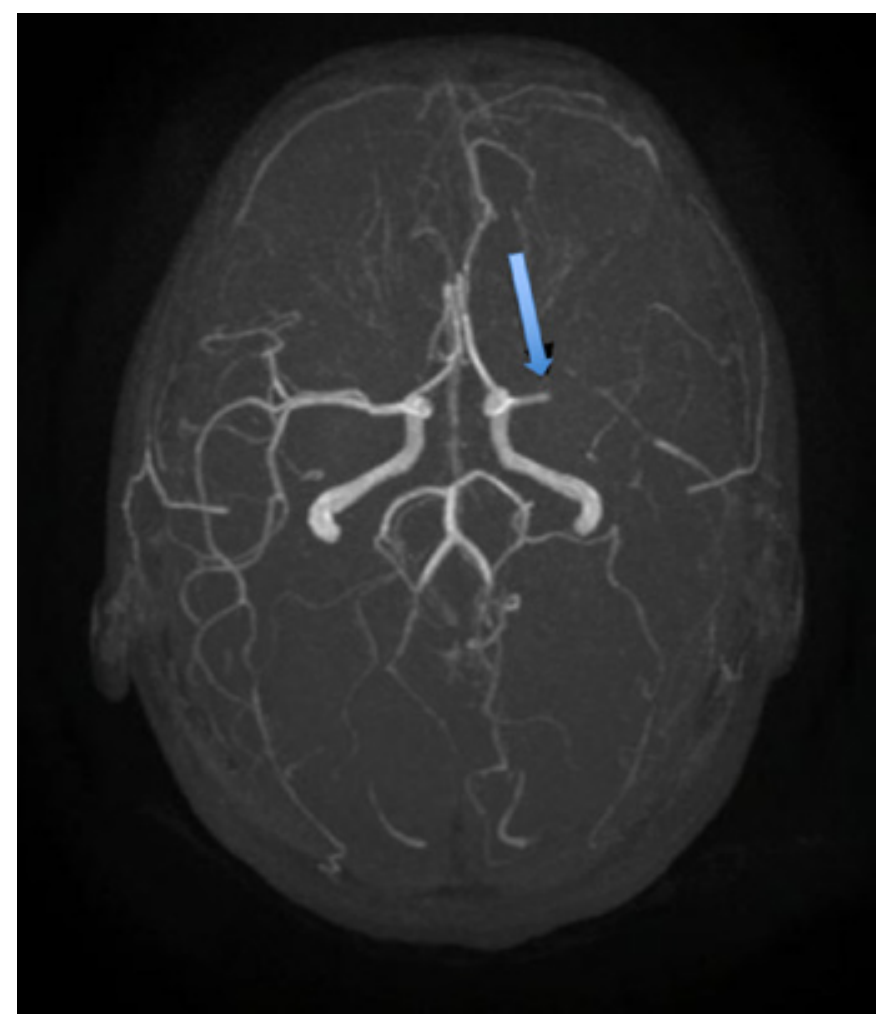

Se observa obstrucción en el flujo de la arteria cerebral media. 
la hepatitis B (anti-core) negativas; anticuerpos contra virus de la hepatitis $C$ totales negativos; virus de inmunodeficiencia humana no reactivo; reagina plasmática rápida negativa; IgM para virus de Epstein-Barr negativa; serología para CMV: Ig M positiva (1,41), IgG positiva (219), PCR negativa; derivado proteico purificado: $0 \mathrm{~mm}$.
Se inició tratamiento antiagregante y anticoagulante con aspirina y heparina de bajo peso molecular. Esta última se cambió por acenocumarol luego de una semana de tratamiento. Dado que el cuadro era un SAF asociado a otras manifestaciones, se comenzó tratamiento con hidroxicloroquina (200 mg/

FIgURA 2. Resonancia magnética de cerebro secuencia FLAIR

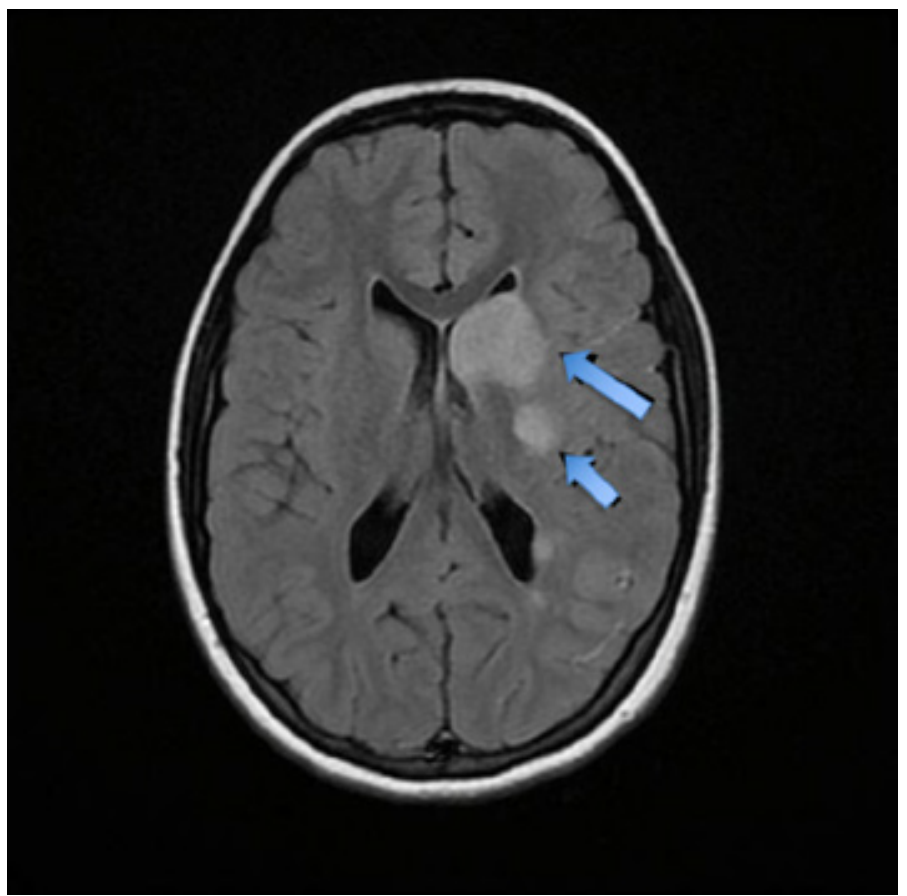

Se visualizan imágenes hiperintensas periventriculares, correspondientes a áreas de isquemia.

TABLA 1. Criterios de clasificación para el sindrome antifosfolipídico ${ }^{4-6}$

Diagnóstico de síndrome antifosfolipídico: al menos uno de los siguientes criterios clínicos y uno de los criterios de laboratorio

\section{Criterios clínicos}

1. Trombosis vascular: uno o más episodios clínicos de trombosis arterial, venosa o de pequeños vasos en cualquier tejido u órgano. Debe estar confirmado por estudios por imágenes, estudio Doppler o histología, excepto la trombosis superficial.

2. Morbilidad en el embarazo:

a. Una o más muertes inexplicables de un feto morfológicamente normal a las 10 semanas o más de gestación.

b. Uno o más partos prematuros de un neonato morfológicamente normal de 34 o menos semanas de gestación secundario a eclampsia o preeclampsia grave o insuficiencia placentaria.

c. Tres o más abortos espontáneos de causa desconocida luego de 10 semanas de gestación, habiéndose excluido anormalidades anatómicas u hormonales maternas o cromosomopatías tanto maternas como paternas.

\section{Criterios de laboratorio}

1. Presencia de anticoagulante lúpico en plasma, en dos o más determinaciones separadas de un lapso de 12 semanas, detectado según las guías de la Sociedad Internacional de Trombosis y Hemostasia.

2. Detección del anticuerpo anticardiolipina IgM o IgG en suero o plasma, presente a títulos medio o alto (más de 40 unidades de IgG fosfolípidos o IgM fosfolípidos o mayor al percentil 99), al menos en dos determinaciones separadas por 12 semanas, medidos por ELISA.

3. Detección del anticuerpo anti- $\beta 2$-glicoproteína IgM o IgG en suero o plasma (título mayor al percentil 99), al menos en dos determinaciones separadas por 12 semanas, medidas por ELISA. 
día) y meprednisona (40 mg/día) como inmunomoduladores. Además, se indicaron sesiones de kinesioterapia para rehabilitación motora.

La paciente evolucionó de manera favorable, con aumento de las plaquetas, hemoglobina y mejora de la función motora. Luego de 18 días de internación, se otorgó el egreso hospitalario con indicaciones de continuar con el mismo tratamiento y control ambulatorio multidisciplinario con neurología, reumatología y hematología.

La paciente sigue en seguimiento ambulatorio multidisciplinario en el hospital.

Dada la presencia de criterios de laboratorio (anemia con prueba de Coombs positiva, ANA positivo y presencia de anticoagulante lúpico), tiene diagnóstico de lupus eritematoso sistémico (LES) y se encuentra en tratamiento con meprednisona en dosis de $2 \mathrm{mg} / \mathrm{kg} /$ día, azatioprina a $50 \mathrm{mg} /$ día e hidroxicloroquina a $200 \mathrm{mg} /$ día. Se suspendió el tratamiento anticoagulante recientemente y se mantiene la antiagregación hasta el momento.

\section{DISCUSIÓN}

El síndrome antifosfolipídico (SAF) es un trastorno trombofílico adquirido en el que se producen anticuerpos contra fosfolípidos y proteínas transportadoras de fosfolípidos. Es infrecuente en la edad pediátrica $(3 \%)$, con un ligero predominio en el sexo femenino $(1,2: 1){ }^{1,2}$

Sus manifestaciones clínicas incluyen la trombosis venosa, arterial y las complicaciones en el embarazo (abortos y partos de pretérmino). Pueden presentarse como eventos aislados o como sucesiones de eventos con evoluciones catastróficas en algunos casos. ${ }^{3}$

El SAF puede aparecer como un fenómeno primario o asociado, principalmente como manifestación de una enfermedad autoinmune como LES, artritis idiopática, polimialgia reumática, enfermedad de Behçet, esclerodermia, poliarteritis nodosa y síndrome de Sjögren, entre otras. En edades pediátricas, el $50 \%$ de los casos son SAF primarios al momento del diagnóstico. Sin embargo, en años posteriores, un $21 \%$ progresará a SAF asociado. ${ }^{2}$

Dentro de las manifestaciones clínicas, se encuentran las clásicas: trombosis venosa $(56 \%)$, trombosis arterial $(34 \%)$, trombosis de pequeños vasos $(7 \%)$ y trombosis mixta $(4 \%)$, y las no clásicas, como trombocitopenia, anemia hemolítica, livedo reticular, corea, mielitis transversa, epilepsia y enfermedad de la válvula cardíaca. Las manifestaciones hematológicas son las más frecuentes dentro de este último grupo. ${ }^{2}$ En el caso de la paciente aquí descrita, presentó una manifestación trombótica arterial asociada a anemia, plaquetopenia y prolongación del KPTT como manifestaciones hematológicas.

Existe una variante conocida como SAF catastrófico que ocurre en menos del $1 \%$ de los casos y se caracteriza por una oclusión acelerada de los pequeños vasos, lo que lleva a una falla multiorgánica. Se define por la afectación de al menos tres órganos o sistemas diferentes en el intervalo de días o semanas, con la demostración de aFL positivos. ${ }^{2}$

El diagnóstico del SAF se realiza sobre la base de una combinación de manifestaciones clínicas y hallazgos en el laboratorio. En 1999 se establecieron los criterios de Saporo para la clasificación de SAF en adultos, los cuales han sido revisados y publicados en el 2006 (Tabla 1). Aunque estos criterios han demostrado especificidad para el diagnóstico de SAF en pediatría, podrían tener baja sensibilidad en este grupo etario.-6

En el caso de la paciente aquí presentada, se arribó al diagnóstico de SAF al reunir un criterio clínico (evento trombótico en el territorio de la arteria cerebral media confirmado por angiorresonancia), asociado al criterio de laboratorio (anticuerpos antifosfolipídicos al momento del diagnóstico y a las 12 semanas).

Con respecto al tratamiento, solo se recomienda profilaxis primaria a los pacientes con títulos elevados de aFL, o que presenten factores de riesgo para trombosis. Se realiza con ácido acetilsalicílico. ${ }^{2,7,8}$ Para la profilaxis secundaria, se recomienda iniciar con heparina de bajo peso molecular, para continuar el tratamiento prolongado con warfarina/ acenocumarol. ${ }^{1} \mathrm{El}$ objetivo de la anticoagulación varía según el antecedente del paciente. El RIN objetivo en los pacientes con trombosis arterial oscila entre 3 y 4 , mientras que el objetivo en los pacientes en profilaxis secundaria por trombosis venosa se encuentra entre 2 y $3 .^{2}$ En pacientes con SAF asociado a conectivopatía (particularmente LES), se recomienda agregar al tratamiento hidroxicloroquina. ${ }^{9}$

En síntesis, si bien el SAF es poco frecuente en la población pediátrica, es importante tenerlo en cuenta en aquellos pacientes con sintomatología compatible con eventos trombóticos de cualquier lecho vascular y prolongación del KPTT, como en 
el caso presentado. También hay que considerarlo frente a otras manifestaciones hematológicas (trombocitopenia, anemia hemolítica), morbilidad en embarazos y pruebas inmunológicas positivas. La sospecha clínica es la base del diagnóstico y la búsqueda de los anticuerpos serán necesarios para la confirmación. No menos importante es el seguimiento longitudinal del paciente para la búsqueda continua de una enfermedad subyacente y la adherencia al tratamiento correspondiente, con el objetivo de evitar recurrencias $y$, de esta manera, disminuir las comorbilidades.

\section{REFERENCIAS}

1. Rumsey DG, Myones B, Massicotte P. Diagnosis and treatment of antiphospholipid syndrome in childhood: A review. Blood Cells Mol Dis. 2017; 67:34-40.

2. Lirola Cruz MJ, Camacho Lovillo M. Síndrome antifosfolípido. Protoc Diagn Ter Pediatr. 2020; 2:141-54.

3. Erkan D, Espinosa G, Cervera R. Catastrophic antiphospholipid syndrome: updated diagnostic algorithms. Autoimmun Rev. 2010; 10(2):74-9.
4. Wincup C, Ioannou Y. The Differences Between Childhood and Adult Onset Antiphospholipid Syndrome. Front Pediatr. 2018; 6:362.

5. Wilson WA, Gharavi AE, Koike T, Lockshin MD, et al. International consensus statement on preliminary classification criteria for definite antiphospholipid syndrome: report of an international workshop. Arthritis Rheum. 1999; 42(7):1309-11.

6. Miyakis S, Lockshin MD, Atsumi T, Branch DW, et al. International consensus Statement on an update of the classification criteria for definite Antiphospholipid Syndrome (APS). J Thromb Haemost. 2006; 4(2):295-306.

7. Arnaud L, Mathian A, Ruffatti A, Erkan D, et al. Efficacy of aspirin for the primary prevention of thrombosis in patients with antiphospholipid antibodies: an international and collaborative meta-analysis. Autoimmun Rev. 2014; 13(3):281-91.

8. Tektonidou MG, Andreoli L, Limper M, Amoura Z, et al. EULAR recommendations for the management of antiphospholipid syndrome in adults. Ann Rheum Dis. 2019; 78(10):1296-1304.

9. TektonidouMG, LaskariK, PanagiotakosDB, Moutsopoulos HM. Risk factors for thrombosis and primary thrombosis prevention in patients with systemic lupus erythematosus with or without antiphospholipid antibodies. Arthritis Rheum. 2009; 61(1):29-36. 